\title{
The Human Interleukin-2 Receptor: Analysis of Structure and Function
}

\author{
WARner C. Greene', Joel M. DePPER ${ }^{2}$, MARTIN KRÖNKE ${ }^{3} \&$ \\ WARREN J. LEONARD ${ }^{4}$
}

\section{INTRODUCTION}

Specific antigens are capable of activating clonal populations of resting $T$ cells when presented by macrophages displaying the appropriate major histocompatibility antigens. This activation sequence is initiated by antigen binding to specific receptors present on the surface of resting $T$ cells. Antigen binding, in the presence of macrophage-derived interleukin-1 (IL-1), then triggers the de novo synthesis and secretion of interleukin-2 (IL-2 or T-cell growth factor) (Morgan et al. 1976) and the transient expression of high and low affinity IL-2 receptors (Smith 1980, Robb 1984, Greene \& Robb 1985, Greene et al. 1986). The subsequent interaction of IL-2 with its high affinity membrane receptor stimulates cellular proliferation, resulting in an expansion of the antigen-reactive clonal T-cell population. This activation process ultimately culminates in the generation of specific effector cells which mediate helper, suppressor, and cytotoxic T-cell functions. The early increase in IL-2 receptor expression is subsequently followed by a decline in receptor number which may play an important regulatory role in the termination of the T-cell immune response. Thus, the specificity, magnitude, and duration of the $\mathrm{T}$-cell immune response is controlled in part through the transient display of IL-2 receptors. IL-2 receptor expression may also play an important role in the normal B-cell immune response (Jung et al. 1984, Tsudo et al. 1984, Waldmann et al. 1984a, Zubler et al. 1984, Nakagawa et al. 1985). Recent studies have demonstrated that activated B cells express high affinity IL-2 receptors and that IL-2 promotes augmented proliferation and differentiation of these cells in vitro.

Progress in the biochemical and molecular characterization of the human IL-2 receptor was facilitated by the identification of monoclonal anti-receptor

\footnotetext{
'Metabolism Branch, National Cancer Institute, National Institutes of Health, Bethesda, Maryland, ${ }^{2}$ University of Michigan Medical School, Ann Arbor, Michigan, U.S.A., ${ }^{3}$ Max Planck Institute, University of Gottingen, Gottingen, West Germany, and ${ }^{4} \mathrm{Cell}$ Biology and Metabolism Branch, National Institute of Child Health and Human Development, National Institutes of Health, Bethesda, Maryland, U.S.A.
} 
antibodies. The first such antibody in the human system was anti-Tac (Uchiyama et al. 1981). Utilizing this antibody, the IL-2 receptor has been biochemically characterized and purified (Leonard et al. 1982, 1983, 1984a, 1985a, Miyawaki et al. 1982, Depper et al. 1983, Robb \& Greene 1983, Wano et al. 1984), cDNAs for the receptor molecularly cloned (Leonard et al. 1984b, Nikaido et al. 1984, Cosman et al. 1984), and the IL-2 receptor gene isolated and its organization and location within the human genome defined (Leonard et al. 1985b, c, Ishida et al. 1985). In addition, deregulated IL-2 receptor expression in leukemic $T$ cells infected with the human $T$ lymphotropic virus types I and II (HTLV-I and -II) has been detected (Gootenberg et al. 1981, Depper et al. 1984a, Waldmann et al. 1984b, Krönke 1985a). Early evidence suggests that these retroviruses contain similar trans-activator genes whose protein products induce the coexpression of the IL-2 and IL-2 receptor genes (Greene et al., 1986b). Thus, subversion of growth control in the early phase of HTLV-I- and -II-mediated leukemic transformation may involve IL-2-IL-2 receptor-mediated autocrine T-cell growth. Salient features of the IL-2 receptor at the protein, mRNA, and gene levels, as well as abnormalities of receptor expression in HTLV-I-infected leukemic T cells, will be considered in the following sections.

\section{IDENTIFICATION OF ANTI-IL-2 RECEPTOR MONOCLONAL ANTIBODIES}

Drs. Takashi Uchiyama and Thomas Waldmann prepared the anti-Tac monoclonal antibody using $T$ cells from the first American patient with HTLV-Iinduced adult T-cell leukemia (ATL) for immunization (Uchiyama et al. 1981). This antibody reacted with activated but not resting $\mathrm{T}$ cells and was therefore named anti-Tac. Subsequent study of the Tac antigen revealed that it was the human IL-2 receptor. Evidence supporting this conclusion included the following findings: (a) anti-Tac blocks IL-2-dependent T-cell proliferation (Leonard et al. 1982); (b) anti-Tac inhibits the binding of radiolabeled IL-2 (Leonard et al. 1982) and IL-2 inhibits the binding of radiolabeled anti-Tac (Robb \& Greene 1983); (c) both immobilized IL-2 and anti-Tac bind the identical 55000 dalton membrane glycoprotein present on activated T cells (Robb \& Greene 1983); and (d) both anti-Tac and anti-IL-2 antibodies precipitate the same 65-70000 dalton protein band produced by covalently crosslinking IL-2 to its receptor (Leonard et al. 1983).

\footnotetext{
Abbreviations:

IL-1 - interleukin-1

IL-2 - interleukin-2

PHA - phytohemagglutinin

PMA - phorbol myristate acetate

HTLV - human T lymphotropic virus

ATL - adult T-cell leukemia
} 
Immunoprecipitations with anti-Tac performed under reducing conditions revealed that the IL-2 receptor was a 50000 dalton glycoprotein on HUT-102B2 cells but a 55000 dalton glycoprotein on normal activated T cells (Leonard 1982, 1983, 1985a, Wano et al. 1984). Under nonreducing conditions, the receptor migrated with a smaller apparent size, suggesting the presence of intrachain disulfide bonds. As discussed in a later section, the difference in apparent $M_{r}$ of the receptor in these cells is produced by altered post-translational processing rather than differences in the primary amino acid sequence.

Other monoclonal antibodies reactive with the human IL-2 receptor have also been identified, including B49.9 (Cotner et al. 1983), 2A3 (Urdal et al. 1984), and 7G7/B6 (Rubin et al. 1985). The first two of these antibodies are similar to anti-Tac; however, 7G7/B6 identifies a distinct receptor epitope which does not interfere with IL-2 binding or action. Each of these three monoclonals reacts with the same 55000 dalton membrane structure precipitated by anti-Tac.

\section{IL-2 RECEPTOR BIOSYNTHESIS}

Pulse-chase radiolabeling studies and analyses employing tunicamyin, endoglycosidase $\mathrm{F}$, and neuraminidase provided considerable insight into the sequential steps of IL-2 receptor biosynthesis. At early time points in pulse-chase studies performed in the presence of tunicamycin to inhibit N-linked glycosylation, a $33000 \mathrm{M}_{\mathrm{r}}$ protein (p33) was immunoprecipitated with anti-Tac (Leonard et al. 1983, 1985a). This protein corresponded to the unmodified IL-2 receptor peptide, which was approximately 1500 daltons smaller than the primary translation product $\left(M_{r} 34500\right)$ generated in a cell-free wheat germ translation system and immunoprecipitated with an anti-receptor heteroantiserum (Leonard et al. 1984b). These data are compatible with cotranslational cleavage of a signal peptide from the primary translation product, thus generating the $33000 \mathrm{Mr}$ protein. As discussed below, a 21-residue signal peptide was subsequently identified by sequence analysis of a full-length IL-2 receptor cDNA (Leonard et al. 1984b, Nikaido et al. 1984, Cosman et al. 1984). Pulse-chase labeling in the absence of tunicamycin did not reveal p33 but rather two larger precursor proteins of $\mathrm{M}_{\mathrm{r}} 35000$ and 37000 (p35 and p37) (Leonard et al. 1983, 1985a). These data suggested that $\mathrm{p} 33$ was cotranslationally processed by $\mathrm{N}$-linked glycosylation to these intermediate forms (Leonard et al. 1983, 1985a). This hypothesis was confirmed in studies employing endoglycosidase $\mathrm{F}$, which cleaves $\mathrm{N}$-linked sugar moieties, which converted the $\mathrm{p} 35 / \mathrm{p} 37$ doublet to $\mathrm{p} 33$. During longer periods of chase, further modifications of $\mathrm{p} 35$ and $\mathrm{p} 37$ were detected. These proteins were exported to the Golgi apparatus where $\mathrm{O}$-linked sugar and sialic acid were added, producing a saltatory increase in apparent receptor size to an $\mathrm{M}_{\mathrm{r}}$ of 55000 . These Golgi-associated processing events were blocked by addition of the carboxylic 
ionophore, monensin, which is known to interfere with protein transport through and processing within the Golgi apparatus (Leonard et al. 1985a).

In addition to the introduction of $\mathrm{N}$ - and $\mathrm{O}$-linked carbohydrate, the IL-2 receptor protein is also post-translationally modified by sulfation (Leonard et al. 1985a). At present, it is unknown whether the sulfate is introduced into carbohydrate (usually N-linked sugar) or protein (occasionally tyrosine residues). However, after $\left.{ }^{35} S\right]$ sulfuric acid labeling and complete hydrolysis of the labeled protein, all of the radioactivity was precipitable with barium chloride, indicating that the label was incorporated as sulfate rather than sulfide. The difference in apparent size of the HUT-102B2 and normal activated T-cell IL-2 receptor ( $50000 \mathrm{M}_{\mathrm{r}}$ versus $55000 \mathrm{M}_{\mathrm{r}}$ ) is at least in part related to diminished addition of sulfate as well as sialic acid to the leukemic receptor protein. The primary translation products, unmodified peptides and $\mathrm{N}$-glycosylated precursors, are identical in size in these two cell types. Thus, the size difference is largely generated during late Golgi or post Golgi processing. Interestingly, both IL-2 and anti-Tac immobilized on bead supports react with p33, p35, and p37 precursor forms of the receptor (Leonard et al. 1985a). Thus, post-translational processing of the IL-2 receptor is not required for IL-2 binding; however, it is possible that these processing events may alter the resultant affinity of the receptor for its ligand.

Following post-translational modification, the mature receptor protein $\left(\mathrm{M}_{\mathrm{r}}\right.$ 55000 in normal activated $\mathrm{T}$ cells) is displayed on the cell surface. Constitutive phosphorylation of the receptor protein has also been detected (Shackelford \& Trowbridge 1984, Leonard et al. 1985a), principally involving serine 247 located within the intracytoplasmic domain. Thus far, convincing evidence for IL-2induced phosphorylation of the receptor has not been obtained; however, this possibility cannot yet be entirely excluded.

\section{MOLECULAR CLONING OF IL-2 RECEPTOR cDNAs}

We approached the problem of isolating IL-2 receptor cDNAs by purifying receptor protein, determining its $\mathrm{N}$-terminal amino acid sequence, and screening a cDNA library with synthetic oligonucleotide probes prepared based on the protein sequence (Leonard et al. 1984b). IL-2 receptor protein was purified from the HUT-102B2 cell line by immunoaffinity chromatography with anti-Tac. This cell line was previously demonstrated to express large numbers of IL-2 receptors (Depper et al. 1984a). The sequence of the $\mathrm{N}$-terminal 29 residues of the protein was determined by gas phase microsequencing using approximately $200 \mathrm{pmol}$ of protein per analysis. The sequence obtained was as follows: $\mathrm{NH}_{2}$-glu-leu-cys-aspasp-asp-pro-pro-glu-ile-pro-his-ala-thr-phe-lys-ala-met-ala-tyr-lys-glu-gly-thr-metleu-asn-cys-glu. Based on residues 3-8 (italicized), a pool of 64 oligonucleotide probes, 17 bases in length, were synthesized. These probes were radiolabeled with ${ }^{32} \mathrm{P}$ and used to screen a $\lambda \mathrm{gt} 10 \mathrm{cDNA}$ library prepared with HUT-102B2 mRNA. 
Following serial screening, several candidate phage clones were identified, and three were selected for further study. These cDNAs were subsequently shown to correspond to the human $\mathrm{IL}-2$ receptor based on selective hybridization of mRNA, DNA sequence analysis, and expression in COS-1 and L cells (Leonard et al. 1984b, Greene et al. 1985).

The two longest clones, denoted pIL2R3 (2.4 kb) and pIL2R4 (1.7 kb) (Leonard et al. 1984b), displayed an interesting difference. Clone 3 contained a region of 216 bases located within the protein coding region which was missing in clone 4. Furthermore, this region was bordered by typical RNA splice donor and acceptor sites, suggesting that the cDNAs might correspond to an unspliced and spliced mRNA. In order to determine which of these clones encoded the IL-2 receptor, both of the cDNA inserts were expressed in COS-1 cells and these cells were evaluated for display of membrane IL-2 receptors. Transfection of clone 3, which retained the 216-base segment, resulted in the production of $50000 \mathrm{M}_{\mathrm{r}}$ receptors which reacted with IL-2 and anti-Tac. In contrast, clone 4 did not direct the membrane display of IL-2 receptors in these cells. Thus far, the protein product of clone 4 has not been identified; however, aberrantly spliced mRNA corresponding to this cDNA has been detected in both normal activated $T$ cells (Leonard et al. 1985d) and HTLV-I-transformed leukemic T-cell lines (Krönke et al. 1985a), indicating that this cDNA does not represent a cloning artifact.

The primary structure of the IL-2 receptor was deduced by sequence analysis of a full-length IL-2 receptor cDNA (Leonard et al. 1984b). The receptor is composed of 272 amino acids, including a 21 -residue hydrophobic signal peptide. Thirteen cysteine residues are present, some of which participate in the formation of intramolecular disulfide bonds. The intergrity of these disulfide bonds is required for anti-Tac and IL-2 binding. Interchain disulfide bonding has not been detected. The receptor contains two consensus sequences for $\mathrm{N}$-linked glycosylation (Asn-X-Ser/Thr) and multiple potential sites for O-linked sugar addition. A hydrophobic, presumably transmembrane, domain composed of 19 residues is present near the carboxy terminus of the protein. Given the position of the signal peptide and $\mathrm{N}$-linked glycosylation sites, the receptor is almost certainly an $\mathrm{NH}_{2}$ terminus out, $\mathrm{COOH}$ terminus in transmembrane structure. An unexpected feature of the IL-2 receptor is that its intracytoplasmic domain is composed of only 13 residues. Thus, in contrast to other growth factor receptors, this intracytoplasmic domain is insufficient in length to encode an enzymatic activity, in particular, a tyrosine kinase. The intracytoplasmic domain, however, does contain six positively charged amino acids which may serve to anchor the receptor protein within the plasma membrane through interactions with the negatively charged phospholipid headgroups. To test this possibility, we have introduced a translation termination codon in the cDNA following the fourth residue of the transmembrane domain. When expressed in mouse fibroblasts, this truncated "anchor minus" IL-2 receptor cDNA exclusively directs the synthesis 
of a secreted form of the IL-2 receptor which retains the capacity to bind IL-2 and anti-Tac (Treiger et al., 1986).

\section{THE IL-2 RECEPTOR GENE}

Utilizing the IL-2 receptor cDNA, phage clones containing the IL-2 receptor gene were isolated from two genomic libraries. Sequence analysis of these phage clones demonstrated that the receptor is composed of eight exons and seven introns and spans a minimum distance of $25 \mathrm{~kb}$ (Leonard et al. 1985b). In situ hybridization studies localized the IL-2 receptor gene to chromosome $10 \mathrm{p}$ band $14 \rightarrow 15$ (Leonard et al. 1985c). To date, karyotypic abnormalities of this region of chromosome 10 have not been associated with human lymphoid malignancies. The first exon of the receptor gene encodes the $5^{\prime}$ untranslated region as well as the 21-amino-acid signal peptide required for transport of the protein into the endoplasmic reticulum. The first intron is quite large, encompassing at least 15 $\mathrm{kb}$. Thus far, phage clones completely bridging the first intron have not been isolated, hence the precise length of the receptor gene is unknown and may be considerably greater than the minimal estimate of $25 \mathrm{~kb}$ provided. The second exon encodes the $\mathrm{N}$-terminal 66 amino acids of the mature receptor protein including one of the two $\mathrm{N}$-glycosylation sites. The third exon contains the next 36 amino acids and the second $\mathrm{N}$-glycosylation site. The fourth exon encodes 72 amino acids which share unexpected homology with the second exon. These data suggest that these exons were derived from an internal gene duplication event. Similar homology is present in the mouse IL-2 receptor (Miller et al. 1985), suggesting that this internal duplication occurred at least 50 million years ago, prior to the genetic radiation of mouse and man. The location and presence of these duplicated domains raises the interesting, though presently unproven, possibility that the IL-2 receptor may contain two ligand-binding sites. The fourth exon is also homologous to the recognition domain of human complement factor B (Ba fragment) (Leonard et al. 1985b). The significance of this unexpected homology is unclear but suggests that exons from these two genes shared an ancestral relationship. The fourth exon also encodes the 216 bases which are infrequently removed by aberrant post-transcriptional splicing, resulting in the joining of exon 3 and exon 5. As noted above, expression of a cDNA corresponding to this aberrantly spliced mRNA, in COS-1 or L cells, does not result in the display of functional membrane IL-2 receptors (Leonard et al. 1984b). These data suggest that the fourth exon is either important for effective translation or transport of the IL-2 receptor or; alternatively, involved in IL-2 and anti-Tac binding. The sixth exon contains multiple potential sites for O-linked glycosylation and, topographically, is located immediately extracytoplasmic to the plasma membrane. A similarly positioned exon rich in O-linked glycosylation sites has been found in the low density lipoprotein receptor (Yamamoto et al. 1984). The 
seventh exon encodes the majority of the 19-residue hydrophobic transmembrane domain, while the eighth exon encodes part of the 13 amino acids comprising the intracytoplasmic domain as well as the $3^{\prime}$ untranslated region of the IL-2 receptor. As discussed below, the $3^{\prime}$ untranslated region contains at least three functional polyadenylation signal sequences as well as the unexpected presence of multiple Alu repetitive elements located between the second and third poly A addition sites (Leonard et al. 1985b).

The $5^{\prime}$ end of the IL-2 receptor mRNAs may also vary. Primer extension and $\mathrm{S} 1$ nuclease protection analyses have demonstrated that activated normal $\mathrm{T}$ cells initiate transcription of receptor mRNA at two discrete sites separated by 58 nucleotides (Leonard et al. 1985b). "TATA-like" promotor sequences are present 25-30 bp upstream from each of these initiation sites. This $5^{\prime}$ flanking region contains functional promotor activity, as evidenced by its capacity to direct the expression of the chloramphenicol-acetyl transferase gene in JURKAT T cells. Each of the two promotors controlling the two transcription initiation sites appears to share nearly equivalent strength in normal activated $\mathrm{T}$ cells. As discussed below, a third transcription initiation site has also been identified in HTLV-I-infected leukemic T cells which display large numbers of IL-2 receptors.

\section{MULTIPLE IL-2 RECEPTOR mRNAs}

Northern blotting analysis of activated T-cell RNA revealed three discrete size classes of IL-2 receptor mRNA (Leonard et al. 1984b). S1 nuclease protection studies indicated that these differently sized mRNAs are produced by the utilization of at least three different $3^{\prime}$ polyadenylation sequences (Krönke et al. 1985a, Leonard et al. 1985d). Suboptimal stimulation of normal $\mathrm{T}$ cells appears to favor use of the most distal poly A site, while maximal stimulation produces more equivalent use of each of the three sites (Krönke et al. 1985a). At present, it is unknown whether certain receptor mRNA species are more stable or more efficiently translated than others. The combination of two transcription initiation sites, the variable post-transcriptional splicing of exon 4 , and the three poly $A$ sites indicates that as many as 12 different IL-2 receptor mRNAs may exist in activated normal $\mathrm{T}$ cells.

\section{IL-2 RECEPTOR EXPRESSION IS TRANSIENT BUT CAN BE REINDUCED}

Activation of resting human $\mathrm{T}$ cells with phytohemagglutinin (PHA) results in the induction of IL-2 receptor expression which peaks at 48 to $72 \mathrm{~h}$ (Depper et al. 1984b). This increase in receptor display and the concomitant production of IL-2 results in T-cell proliferation. However, with longer periods in culture, IL2 receptor levels decline and cellular proliferation diminishes (Cantrell \& Smith 1983, Depper et al. 1984b). Following 10 to $12 \mathrm{~d}$ in culture, $80-90 \%$ of the IL- 
2 receptors are lost. The transient nature of IL-2 receptor expression may play an important role both in the development and in the termination of the T-cell immune response.

To dissect the regulation of this transient IL-2 receptor expression, peripheral blood lymphocytes were stimulated with PHA for varying periods of time and their RNA isolated. These RNAs were then analyzed by Northern blotting and hybridization with radiolabeled IL-2 receptor cDNA. Mature IL-2 receptor mRNA was detected within 4 to $8 \mathrm{~h}$ after PHA stimulation (Leonard et al. 1985d). A larger RNA species, possibly a nuclear precursor, was produced within $2 \mathrm{~h}$ and disappeared as the mature mRNA forms emerged. After peaking at 8 to $24 \mathrm{~h}$, receptor mRNA levels then declined. Nuclear runoff studies indicate that the rise and fall in whole cell IL-2 receptor mRNA levels reflected, at least in part, a rise and fall in the transcriptional activity of the IL-2 receptor gene (Leonard et al. 1985d). Interestingly, whole cell mRNA levels appeared to decline somewhat earlier than the fall in receptor gene transcription, raising the possibility that post-transcriptional regulation of IL-2 receptor expression may also occur.

These cultured nonproliferating $\mathrm{T}$ cells that have lost the majority of their IL2 receptors, however, remain susceptible to signals which stimulate IL- 2 receptor reexpression and a second round of cellular proliferation (Cantrell \& Smith 1983, Depper et al. 1984b, 1985a, Malek \& Ashwell 1985, Smith \& Cantrell 1985). Three general types of activation signals capable of inducing IL-2 receptor reexpression have been defined. First, reexposure of the cells to mitogenic lectin (Depper et al. 1984b, 1985b) or antigen (Hemler et al. 1984, Kaplan et al. 1984, Reske-Kunz et al. 1984) produces upregulation of IL-2 receptor expression. For example, PHA restimulation produces a 2-to-10-fold increase in receptor number within $24 \mathrm{~h}$. Actinomycin D and cycloheximide block this mitogen-induced reexpression of receptors, suggesting that the response is dependent upon de novo RNA and protein synthesis. Thus, IL-2 receptor reexpression is not solely mediated by the transport of preformed intracellular receptors to the cell surface. Second, stimulation with the phorbol ester, phorbol myristate acetate (PMA), also augments IL-2 receptor expression (Depper et al. 1984b, 1985b). Furthermore, phospholipase $\mathrm{C}$ and synthetic congeners of diacylglycerol increase IL-2 receptor expression. Each of these agents interacts with protein kinase $C$, suggesting a possible regulatory role for this enzyme in IL-2 receptor expression. Finally, addition of IL-2 itself augments IL-2 receptor display (Depper et al. 1985a, Malek \& Ashwell 1985, Smith \& Cantrell 1985). IL-2 amplification of IL-2 receptor expression has also been described in freshly isolated, resting $\mathrm{T}$ lymphocytes (Reem \& Yeh 1984, Welte et al. 1984). Similarly, IL-2-induced increases in IL-2 receptor number have been demonstrated in a cloned B-cell line (5B4) which constitutively expresses small numbers of IL-2 receptors (Waldmann et al. 1984a). These effects of IL-2 are produced at ligand concentrations which preferentially titrate the high, but not low, affinity class of IL-2 receptors (see later section 
for discussion of high and low affinity receptors). Low affinity receptors are preferentially induced in these reexpression experiments; however, the resultant proliferation suggests that functional high affinity receptors are also induced. It is possible that high affinity receptor detection is complicated by the recently recognized receptor-mediated endocytosis of the high, but not low, affinity class of receptors (Weissman et al. 1986).

Analyses at the RNA level indicated that PHA, PMA, and IL-2 each augmented IL-2 receptor mRNA production. IL-2-induced increases in receptor gene transcription were also demonstrated in nuclear runoff assays (Depper et al. 1985a). IL-2 activation of these cells produced concomitant increases in the levels of c-myc and transferrin receptor mRNAs, but did not alter T-cell antigen $(\beta$ chain) receptor mRNA levels. The reinduction of $1 \mathrm{~L}-2$ receptor display by PHA, PMA, and IL-2 was followed by a decline at 48 to $72 \mathrm{~h}$, indicating that receptor reexpression is also a transient, nonsustained phenomenon. Despite the ability of IL-2 to upregulate IL-2 receptor expression in T cells cultured for 10 to $12 \mathrm{~d}$, this ligand does not block the initial and physiologic decline in receptor levels occurring after $72 \mathrm{~h}$ of activation. This finding may reflect active but transient repression of IL-2 receptor gene transcription resulting in the initial decline in receptor number. A similar model of repression has been proposed to explain the transient expression of the IL-2 gene in activated T cells (Efrat \& Kaempfer 1984).

\section{SEQUENTIAL GENE EXPRESSION DURING T-LYMPHOCYTE ACTIVATION}

Nuclear transcription studies have also been used to define a temporal sequence of gene activation in human T cells stimulated with PHA and PMA (Krönke et al. 1985b). These studies indicated that the proto-oncogene, c-myc, is activated rapidly reaching peak transcription within 6 to $9 \mathrm{~h}$. These findings are consistent with the earlier studies of Kelly et al. (1983). c-myc expression is followed by IL2 receptor and interferon-gamma transcription which peaks at 9 to $15 \mathrm{~h}$. IL-2 gene transcription is also initiated early but does not reach maximal levels until $24 \mathrm{~h}$. Transcription of these four genes was not inhibited by the addition of cycloheximide, indicating that gene expression was not dependent upon the protein products of the other genes. For example, the c-myc protein was not required for transcription of the IL-2 gene. In contrast, the transferrin receptor gene was not expressed until $24 \mathrm{~h}$ after mitogen activation and did not reach peak levels until $48 \mathrm{~h}$. Addition of cycloheximide at the initiation of culture completely blocked transferrin receptor gene transcription, suggesting a dependence on protein synthesis. These results are in agreement with the studies of Neckers and Cossman who have reported that transferrin receptor expression is mediated by a prior interaction of IL-2 with its cellular receptor (Neckers \& Cossman 1983). 


\section{IL-2 RECEPTOR EXPRESSION ON ACTIVATED B CELLS}

Although early evidence suggested that IL-2 receptor expression was a unique property of activated $\mathrm{T}$ lymphocytes, various lines of evidence have emerged demonstrating that IL-2 receptors are also present on some activated B cells (Korsmeyer et al. 1983, Greene et al. 1983, Jung et al. 1984, Tsudo et al. 1984, Waldmann et al. 1984a, Zubler et al. 1984, Lowenthal et al. 1985, Mittler et al. 1985, Nakagawa et al. 1985). Furthermore, the interaction of IL-2 with these receptors may play an important role in B-cell growth and differentiation. Low levels of radiolabeled anti-Tac binding were initially detected on certain Burkitt B lymphoma cell lines (unpublished observations). Subsequently, Ortega et al. (1984) demonstrated IL-2 receptors on lipopolysaccharide-stimulated murine B lymphoblasts. Furthermore, several hairy cell leukemia B-cell tumors (Korsmeyer et al. 1983, Greene et al. 1983), displaying productive heavy and light chain immunoglobulin gene rearrangements, were shown to express Tac antigen. Subsequently, several investigators have demonstrated that IL-2 may induce both proliferation and/or differentiation of normal activated B cells (Jung et al. 1984, Tsudo et al. 1984, Zubler et al. 1984, Mittler et al. 1985, Nakagawa et al. 1985). Waldmann et al. (1984a) provided evidence for high affinity IL-2 receptors on a cloned, activated B-cell line and demonstrated that IL-2 could upregulate the number of these receptors and augment immunoglobulin production. High affinity IL-2 receptors on B cells were also quantitated by Lowenthal and coworkers (1985). Despite these findings, the role of IL-2 in in vivo B-cell differentiation and proliferation remains unresolved; however, in vitro it is now clear that activated B cells may both display specific high affinity IL-2 receptors and functionally respond to purified IL-2.

\section{HIGH AND LOW AFFINITY FORMS OF THE IL-2 RECEPTOR}

The initial IL-2 receptor binding assays performed by Robb and associates (1981) with purified radiolabeled IL-2 revealed 2000 to 4000 receptors on the surface of PHA-activated T lymphoblasts. IL-2 interacted with these sites with unexpectedly high affinity (Kd of 2 to $10 \mathrm{pM}$ ). In contrast, binding studies performed with radiolabeled anti-Tac antibody suggested 30000 to 60000 IL-2 receptors per PHA-activated T cell (Depper et al. 1984b). Scatchard analysis of anti-Tac binding suggested a single affinity class of receptors $\left(\mathrm{Kd} 10^{-9}\right.$ to $\left.10^{-10} \mathrm{M}\right)$. This difference in apparent receptor number was not due to $\mathrm{Fc}$ receptor binding by anti-Tac or secondary to occupancy of potential receptor sites by endogenously produced IL-2, and there were no apparent errors in the estimation of the specific activities of the two radiolabeled ligands. These findings suggested the possibility that different affinity forms of the IL-2 receptor might exist. To examine this hypothesis, the IL-2 binding studies were performed over a much broader range of 
ligand concentrations (Robb et al. 1984). These assays demonstrated a previously undetected large pool of IL-2 receptors which bound IL-2 with a 1000- to 10000 fold lower apparent affinity. Similar data supporting high and low affinity forms of the IL-2 receptor were subsequently provided by Lowenthal and colleagues (1985); however, these authors found that the affinity difference in the two classes was less marked (100-fold rather than 1000- to 10000 -fold) and proposed that the conditions of washing might produce this difference. When summed, the number of high and low affinity IL-2 binding sites approximated the number of Tac sites within a factor of 2 . These data suggest that anti-Tac reacts equivalently with both the high and low affinity forms of the IL-2 receptor and thus cannot be used to distinguish these different receptor classes. Interestingly, while the high affinity receptors represent only 5 to $10 \%$ of the total membrane IL-2 receptors, these sites appear to exclusively mediate the growth-promoting response to IL-2 (Robb et al. 1981, 1984). The function, if any, of the more numerous low affinity receptors remains unknown. Weissman and colleagues (1986) have demonstrated that the high affinity, but not low affinity, IL-2 receptors undergo receptor-mediated endocytosis, further defining a basic functional difference in these receptor classes.

The structural features which distinguish the high and low affinity IL-2 receptors have not been elucidated; however, three possibilities merit consideration. First, the high affinity IL-2 receptor could be generated by the assembly of a receptor complex involving one or more other proteins. This model is particularly attractive in terms of providing a mechanism for growth signal transduction, since the intracytoplasmic domain of the IL-2 binding protein is only 13 amino acids in length. It is possible that the other putative protein(s) in the receptor complex may not only augment receptor affinity but also provide a key component(s) involved in signal transmission. A second possibility is that the high affinity IL-2 receptor is produced by a particular form of post-translational processing. This model, however, does not address the problems of signal transduction. A third possibility is that the high and low affinity forms of the IL-2 receptor are different proteins encoded by different genes. In this regard, expression of the human IL-2 receptor cDNA in mouse fibroblasts results in the expression of only low affinity receptors (Greene et al. 1985). Notwithstanding, in the human system, both the high and low affinity receptor proteins share reactivity with anti-Tac; in the mouse system both receptors share epitopes for two different monoclonal antibodies, 3C7 and 7D4 (Malek et al. 1983). Thus, if different proteins exist, they must be similar in terms of sharing these monoclonal binding sites. Recent studies involving expression of human IL-2 receptor cDNA in mouse $\mathrm{T}$ cells have demonstrated that this cDNA is capable of directing the synthesis of both high and low affinity receptors (Hatakeyama et al. 1985). These data provide convincing evidence against the two-gene hypothesis for high and low affinity receptors. The data further indicate that either the necessary com- 
panion proteins required for high affinity receptor formation are present in $\mathrm{T}$ lymphocytes but not fibroblasts or, alternatively, that the required post-translational modification involved in high affinity receptor expression occurs in $\mathrm{T}$ cells but not in fibroblasts.

\section{DEREGULATED IL-2 RECEPTOR EXPRESSION IN HTLV-I-INDUCED T-CELL LEUKEMIA}

HTLV-I is the primary etiologic agent in the adult T-cell leukemia (ATL) (Poiesz et al. 1980, 1981, Gallo \& Wong-Staal 1982, Yoshida et al. 1982). Clinically, patients with this aggressive and usually fatal leukemia may present with hypercalcemia, osteolytic bone lesions, dermal or epidermal tumor infiltrates, and opportunistic infections (Uchiyama et al. 1977, Bunn et al. 1983). Geographically, ATL is clustered in areas where HTLV-I is endemic, including the southwestern region of Japan, the Caribbean basin, the southeastern United States, and sub-Saharan Africa. Thus far, effective forms of therapy for this leukemia have not been identified. HTLV-I primarily infects $\mathrm{T}^{+}{ }^{+} \mathrm{T}$ cells (helper phenotype); however, functionally many ATL cell lines display suppressor T-cell activity (Waldmann et al. 1984b). A uniform finding with cultured ATL cell lines is the expression of large numbers of IL-2 receptors (Gootenberg et al. 1981, Depper et al. 1984a). Both high and low affinity receptors are present, and the total receptor number is usually 5 - to 10 -fold greater than that present on normal $\mathrm{T}$ cells activated with PHA (30000 to 60000 receptors per cell) (Depper et al. 1984a). The majority of these long-term ATL cell lines, while displaying IL-2 receptors, neither secrete IL-2 nor contain detectable amounts of IL-2 mRNA (Arya et al. 1984). Furthermore, many of these cell lines grow in culture independent of exogenous IL-2.

The deregulated expression of IL-2 receptors in these ATL cell lines has been studied in considerable detail. Receptor display is not the result of chromosomal translocation, rearrangement, or amplification of the IL-2 receptor gene (Krönke et al. 1985a). Furthermore, the leukemic and normal IL-2 receptor proteins appear to share identical amino acid sequences (Leonard et al. 1985b); however, some size heterogeneity of receptors has been delineated (e.g., HUT-102 cells) and is produced by differences in post-translational processing. ATL cell lines constitutively express large quantities of IL-2 receptor mRNA, and each of the three known poly $\mathrm{A}$ addition sites are utilized in a pattern characteristic of maximally activated $\mathrm{T}$ cells (Krönke et al. 1985a). Aberrant post-transcriptional splicing of exon 4 has been detected in all ATL cell lines studied, as well as in normal activated $\mathrm{T}$ cells. Thus, no evidence has been obtained for dramatic differences in the post-transcriptional processing of IL-2 receptor mRNA in these ATL cells. Nuclear transcription assays have confirmed high level IL-2 receptor gene expression in ATL cells. Paradoxically, the addition of PHA and PMA, mitogenic agents which activate $\mathrm{IL}-2$ receptor expression in normal $\mathrm{T}$ cells, 
produces partial inhibition (60 to $70 \%$ ) of IL-2 receptor gene transcription in two different ATL cell lines (Krönke et al. 1985a). The molecular mechanism of this inhibition of receptor gene transcription remains undefined at present but might involve mitogen activation of a repressor system which could also mediate the physiological decline of IL-2 receptors occurring during the normal T-cell immune response.

Comparison of the sites of IL-2 receptor transcription initiation in normal and ATL cells has revealed an interesting difference (Leonard et al. 1985b). As noted earlier, IL-2 receptor gene transcription in activated normal T cells is initiated at two principal sites. In contrast, while utilizing these two sites, transcription is also initiated from a third more 5 ' site in ATL cells (Leonard et al. 1985b). The presence of a unique transcription site in these leukemic cells is intriguing in view of high level receptor expression; however, this site is utilized less frequently than the two principal sites present in both normal and ATL cells. While it is conceivable that the mRNAs generated from the third transcription initiation site are more stable or perhaps more efficiently translated, we feel it is unlikely that this third promotor provides a full explanation for the high level expression of IL-2 receptors encountered in this leukemia.

HTLV-I, while capable of acutely transforming human cord blood $\mathrm{T}$ cells, does not contain a recognized oncogene characteristically present in other acutely transforming animal retroviruses (Wong-Staal \& Gallo 1985). In addition, HTLVI does not appear to transform $\mathrm{T}$ cells by insertion near an endogenous cellular oncogene since the sites of proviral integration vary from tumor to tumor (Seiki et al. 1984). DNA sequence analysis of HTLV-I proviruses has revealed the expected gag, pol, and env genes in addition to typical retroviral LTR segments. However, an extra region, termed $\mathrm{pX}$, has also been identified near the 3 ' end of the virus (Seiki et al. 1983, 1985, Haseltine et al. 1984, Kiyokawa et al. 1984, Sodroski et al. 1984, Shimotohno et al. 1985, Wachsman et al. 1985). Sodroski and colleagues (1984) subsequently demonstrated that an open reading frame contained within the $\mathrm{pX}$ region encoded a protein which was capable of activating in trans the transcription of genes controlled by the viral LTR. This transactivator gene was originally termed LOR or X-LOR but was more recently renamed tat ( $t$ ransactivation of transcription) in view of its apparent function. Increasing interest has centered on the possibility that the tat protein may not only augment viral transcription, but also activate the expression of various cellular genes involved in T-cell transformation. The IL-2 receptor gene represents one such candidate cellular target for tat activation. To test this possibility, the tat gene of HTLV-II has been inserted into a retroviral vector (ZIP-NEO), passed through an amphotropic packaging line (psi AM), and used to infect JURKAT T cells and RAJI B cells (Greene et al., 1986b). As an additional control, the tat-II gene was also introduced into the ZIP-NEO retrovirus in the anti-sense orientation. JURKAT $\mathrm{T}$ cells producing functional tat-II protein were identified 
by their capacity to transactivate the HTLV-I LTR. These cells were then evaluated for changes in IL-2 receptor expression. Northern blot analyses of poly $\mathrm{A}^{+}$ RNA demonstrated the presence of IL-2 receptor mRNA in the JURKAT T cells containing the tat-II gene in the sense orientation (Greene et al., 1986b). In contrast, IL-2 receptor mRNA was not detectable in the parental JURKAT T cells, in JURKAT T cells containing the anti-sense tat-II gene, or in JURKAT $\mathrm{T}$ cells containing the tat-III gene isolated from the HTLV-III/LAV retrovirus. In contrast to JURKAT T cells, introduction of the tat-II gene into RAJI B cells did not produce activation of IL-2 receptor expression.

In addition to IL-2 receptor mRNA, IL-2 receptor protein was also detectable in the JURKAT-tat-II $T$ cells. Indirect immunofluorescent studies as well as immunoprecipitation with anti-Tac demonstrated the presence of the Tac antigen in the sense but not the anti-sense JURKAT-tat-II T cells. $\left[{ }^{3} \mathrm{H}\right]$ anti-Tac binding studies revealed the presence of 1000 to $1500 \mathrm{IL}-2$ receptor sites in these cells. In contrast, HUT-102B2 cells, which contain the entire provirus, display 100-fold more receptors. This difference in the magnitude of IL-2 receptor expression is not well understood but may reflect intrinsic properties of the parental JURKAT $T$ cells used for infection. Alternatively, the ZIP-NEO retrovirus used in these studies to introduce the tat-II gene contains a Moloney virus LTR which is not susceptible to trans-activation by the tat-II protein. Thus, unlike the HTLV-I or II provirus where the tat protein trans-activates its own production, tat-II does not augment its expression in the ZIP-NEO retroviral vector. Immunoprecipitation studies have confirmed that the JURKAT-tat-II T cells contain considerably less tat-II protein than HTLV-I-infected ATL cell lines. It is possible that high levels of the tat protein are necessary for full activation of IL-2 receptor expression.

The tat-II-infected cells were also evaluated for activation of other genes. The levels of class I major histocompatibility antigen mRNA and actin mRNA were not significantly changed in these cells. Of interest, the tat-II protein also induced IL-2 gene expression in JURKAT T cells but not in RAJI B cells. These findings raise the intriguing possibility that the tat-II protein may alter normal growth of $\mathrm{T}$ cells by stimulating autocrine proliferation via the activation of IL-2 and IL2 receptor gene expression. However, as noted earlier, the majority of HTLV-Iinfected ATL cell lines, as well as freshly isolated tumor cells from ATL patients, neither secrete IL-2 nor contain detectable levels of IL-2 mRNA (Arya et al. 1984). Furthermore, the majority of long-term cultured ATL cell lines are not dependent on IL-2 for growth. These conflicting findings could be explained by a progression of ATL tumor cells from an early growth factor-dependent stage to a later growth factor-independent stage. Precedence for such a model exists in many other tumor systems; however, the event(s) which permits transition from growth factor dependence to independence is not well understood in these systems. In ATL cells, this transition would appear to involve persistent high level 
IL-2 receptor display and a loss of IL-2 gene expression which is no longer required for growth.

The action of the tat gene of HTLV-II may represent a novel retroviral strategy for perturbing normal growth controls. Retroviruses have now been associated with the introduction of oncogenes resembling growth factors ( $\mathrm{v}-\mathrm{sis} \rightarrow$ plateletderived growth factor) or growth factor receptors ( $v$-erb-B $\rightarrow$ truncated epidermal growth factor receptor). In addition, retroviruses may produce leukemic transformation by cis-activation of an endogenous cellular oncogene via promotorenhancer insertion (e.g., avian leukosis virus activation of c-myc expression). In contrast, the HTLV-I and -II retroviruses may employ a third strategy involving the production of a trans-acting protein which is capable of activating the expression of the cellular genes encoding a growth factor (IL-2) and its receptor.

As noted earlier, no effective treatment for ATL has been defined. Krönke and colleagues (1985c) have recently demonstrated that anti-Tac antibody conjugated to the A chain of ricin toxin is an effective cytotoxic agent in vitro against HTLVI-infected T cells. Similarly, FitzGerald et al. (1984) have demonstrated cytotoxic properties of anti-Tac coupled to Pseudomonas exotoxin for these cells. Though in vitro results with immunotoxins certainly do not predict in vivo success, clinical trials of such anti-Tac-toxin conjugates seem appropriate. Presently, anti-TacPseudomonas exotoxin is being used by Dr. Thomas Waldmann and colleagues at the National Cancer Institute in an experimental protocol involving ATL patients.

\section{SUMMARY}

Considerable information presently exists regarding the molecular, biochemical, and biological features of the human IL-2 receptor. The IL-2 receptor protein, multiple receptor mRNAs, and a single structural gene have now been identified. The important role of this receptor in normal $\mathrm{T}$-cell growth is well established and its potential participation in B-cell growth and differentiation appreciated. The availability of cloned gene products for both the IL-2 receptor and IL-2 may permit the future development of novel biological agents capable of either augmenting or blunting the T-cell immune response. The intriguing interrelationship of HTLV-I and -II infection and altered IL-2 receptor expression is now being unraveled. However, the structural difference in high and low affinity receptors as well as the mechanism by which signals for T-cell growth are propagated through the high affinity receptor remain dominant, unanswered questions in the field.

\section{REFERENCES}

Arya, S. K., Wong-Staal, F. \& Gallo, R. C. (1984) T-cell growth factor gene: lack of expression in human T cell leukemia lymphoma virus infected cells. Science 223, 1086. 
Bunn, P. A., Schechter, G. P., Jaffe, E., Blayney, D., Young, R. C., Matthews, M. J., Blattner, W., Broder, S., Robert-Guroff, M. \& Gallo, R. C. (1983) Clinical course of retrovirus associated adult $\mathrm{T}$ cell lymphoma in the United States. N. Engl. J. Med. $309,257$.

Cantrell, D. A. \& Smith, K. A. (1983) Transient expression of interleukin 2 receptors. Consequences for T cell growth. J. Exp. Med. 158, 1895.

Cosman, D., Ceretti, D. P., Larsen, A., Park, L., March, C., Dower, S., Gillis, S. \& Urdal, D. (1984) Cloning, sequence and expression of human interleukin 2 receptor. Nature 321, 768.

Cotner, T., Williams, J. M., Christenson, L., Shapiro, H. M., Strom, T. B. \& Strominger, J. (1983) Simultaneous flow cytometric analysis of human $T$ cell activation antigen expression and DNA content. J. Exp. Med. 157, 461.

Depper, J. M., Leonard, W. J., Drogula, C., Krönke, M., Waldmann, T. A. \& Greene, W. C. (1985a) Interleukin-2 (IL-2) augments transcription of the interleukin-2 receptor gene. Proc. Natl. Acad. Sci. USA 82, 4230.

Depper, J. M., Leonard, W. J., Krönke, M., Drogula, C., Waldmann, T. A. \& Greene, W. C. (1985b) Activators of protein kinase C and 5-azacytidine induce IL-2 receptor expression in human T lymphocytes. J. Cell. Biochem. 27, 267.

Depper, J. M., Leonard, W. J., Krönke, M., Noguchi, P. D., Cunningham, R. E., Waldmann, T. A. \& Greene, W. C. (1984b) Regulation of interleukin 2 receptor expression: effects of phorbol diester, phospholipase $\mathrm{C}$, and reexposure to lectin and antigen. J. Immunol. 133, 3054.

Depper, J. M., Leonard, W. J., Krönke, M., Waldmann, T. A. \& Greene, W. C. (1984a) Augmented T cell growth factor receptor expression in HTLV-1-infected human leukemic T cells. J. Immunol. 133, 1691.

Depper, J. M., Leonard, W. J., Robb, R. J., Waldmann, T. A. \& Greene, W. C. (1983) Blockade of the interleukin-2 receptor by anti-Tac antibody: inhibition of human lymphocyte activation. J. Immunol. 131, 690 .

Efrat, S. \& Kaempfer, R. (1984) Control of biologically active interleukin 2 messenger RNA formation in induced human lymphocytes. Proc. Natl. Acad. Sci. USA 81, 2601.

FitzGerald, D., Waldmann, T. A., Willingham, M. C. \& Pastan, I. (1984) Pseudomonas exotoxin-anti-Tac cell specific immunotoxin, active against cells expressing the T-cell growth factor receptor. J. Clin. Invest. 74, 966.

Gallo, R. C. \& Wong-Staal, R. (1982) Retroviruses as etiologic agents of some animal and human leukemias and lymphomas and as tools for elucidating the molecular mechanism of leukemogenesis. Blood 60, 545.

Gootenberg, J. E., Ruscetti, F. W., Mier, J. W., Gazdar, A. \& Gallo, R. C. (1981) Human cutaneous $\mathrm{T}$ cell lymphoma and leukemic cell lines produce and respond to $\mathrm{T}$ cell growth factor. J. Exp. Med. 154, 1403.

Greene, W. C., Leonard, W. J. \& Depper, J. M. (1986) Growth of human T lymphocytes: an analysis of interleukin-2 and its cellular receptor. In: Progress in Hematology, Vol. $X I V$, Brown, E. B., ed., pp. 281-301. Grune \& Stratton, Orlando, Fl.

Greene, W. C., Leonard, W. J., Wano, Y., Svetlik, P., Peffer, N. J., Sodroski, J. G., Rosen, C. A. \& Haseltine, W. A. (1986b) The transactivator gene of human T lymphotropic virus type II (HTLV-II) induces interleukin-2 receptor and interleukin-2 cellular gene expression. Science 232: 877.

Greene, W. C. \& Robb, R. J. (1985) Receptors for T-cell growth factor: structure, function and expression on normal and neoplastic cells. In: Contemporary Topics in Molecular Immunology, Vol. 10, Gillis, S. \& Inman, F. P., eds., pp. 1-34. Plenum Press, New York.

Greene, W. C., Robb, R. J., Svetlik, P. B., Rusk, C. M. Depper, J. M. \& Leonard, W. J. 
(1985) Stable expression of cDNA encoding the human interleukin receptor in eukaryotic cells. J. Exp. Med. 162, 363.

Greene, W. C., Waldmann, T. A., Cossman, J., Hsu, S.-M., Neckers, L. M., Marshall, S. L., Jensen, J. P., Bakhshi, A., Leonard, W. J., Depper, J. M., Jaffe, E. S. \& Korsmeyer, S. J. (1983) Hairy cell leukemia: a malignant expansion of B cells which express Tac antigen. In: Normal and Neoplastic Hematopoiesis, Marx, P. \& Golde, D., eds., pp. 501-511. Alan Liss, New York.

Haseltine, W. A., Sodroski, J., Patarca, R., Briggs, D., Perkins, D. \& Wong-Staal, F. (1984) Structure of the $3^{\prime}$ terminal repeat region of type II human $T$ lymphotropic virus: evidence for a new coding region. Science $225,419$.

Hatakeyama, M., Minamoto, S., Uchiyama, T., Hardy, R. R., Yamada, G. \& Taniguchi, T. (1985) Reconstitution of functional IL-2 receptor for human interleukin-2 in mouse cells. Nature 318, 467.

Hemler, M. D., Brenner, M. B., McLean, J. M. \& Strominger, J. L. (1984) Antigen stimulation regulates the level of expression of IL-2 receptors on human T cells. Proc. Natl. Acad. Sci. USA 81, 2172.

Ishida, N., Kanamori, H., Noma, T., Nikaido, T., Sabe, H., Suzuki, N., Shimizu, A. \& Honjo T. (1985) Molecular cloning and structure of the human interleukin-2 gene. Nucleic Acids Res. 13, 7579.

Jung, L., Hara, T. \& Fu, S. M. (1984) Detection and functional studies of p60-65 (Tac antigen) on activated human B cells. J. Exp. Med. 160, 1597.

Kaplan, D. R., Braciale, U. L. \& Braciale, T. J. (1984) Antigen dependent regulation of interleukin 2 receptor expression on cloned human cytotoxic T lymphocytes. J. Immunol. 133, 1966.

Kelly, K., Cochran, B. H., Stiles, C. D. \& Leder, P. (1983) Cell specific regulation of the c-myc gene by lymphocyte mitogens and platelet derived growth factor. Cell 35, 603.

Kiyokawa, T., Seiki, M., Imagawa, K., Shimizu, F. \& Yoshida, M. (1984) Identification of a protein $\left(\mathrm{p} 40^{*}\right)$ encoded by a unique sequence $\mathrm{pX}$ of human $\mathrm{T}$ cell leukemia virus type I. Gann 75, 747.

Korsmeyer, S. J., Greene, W. C., Cossman, J., Hsu, S.-M., Jensen, J. P., Neckers, L. M., Marshall, S. L., Bakhshi, A., Depper, J. M., Leonard, W. J., Jaffe, E. S. \& Waldmann, T. A. (1983) Rearrangement and expression of immunoglobulin genes and expression of Tac antigen in hairy cell leukemia. Proc. Natl. Acad. Sci. USA 80, 4522.

Krönke, M., Depper, J. M., Leonard, W. J., Vitetta, E. S., Waldmann, T. A. \& Greene, W. C. (1985c) Adult $T$ cell leukemia: a potential target for ricin A chain immunotoxins. Blood 65, 1416.

Krönke, M., Leonard, W. J., Depper, J. M. \& Greene, W. C. (1985a) Deregulation of interleukin receptor gene expression in HTLV-1 induced adult T cell leukemia. Science 228, 1215.

Krönke, M., Leonard, W. J., Depper, J. M. \& Greene, W. C. (1985b) Sequential expression of genes involved in human T lymphocyte growth and differentiation. J. Exp. Med. $161,1593$.

Leonard, W. J., Depper, J. M., Uchiyama, T., Smith, K. A., Waldmann, T. A. \& Greene, W. C. (1982) A monoclonal antibody that appears to recognize the receptor for human T-cell growth factor; partial characterization of the receptor. Nature 300, 267.

Leonard, W. J., Depper, J. M., Crabtree, G. R., Rudikoff, S., Pumphrey, J., Robb, R. J., Krönke, M., Svetlik, P. B., Peffer, N. J., Waldmann, T. A. \& Greene, W. C. (1984b) Molecular cloning and expression of cDNAs for the human interleukin-2 receptor. Nature 311, 626.

Leonard, W. J., Depper, J. M., Krönke, M., Peffer, N. J., Svetlik, P. B., Kanehisa, M., Sullivan, M. \& Greene, W. C. (1985b) Structure of the human interleukin-2 receptor gene. Science 230, 633. 
Leonard, W. J., Depper, J. M., Krönke, M., Robb, R. J., Waldmann, T. A. \& Greene, W. C. (1985a) The human receptor for T-cell growth factor: evidence for variable post translational processing, phosphorylation, sulfation and the ability of precursor forms of the receptor to bind T-cell growth factor. J. Biol. Chem. 260, 1872.

Leonard, W. J., Depper, J. M., Robb, R. J., Waldmann, T. A. \& Greene, W. C. (1983) Characterization of the human receptor for T cell growth factor. Proc. Natl. Acad. Sci. USA 80, 6957.

Leonard, W. J., Depper, J. M., Waldmann, T. A. \& Greene, W. C. (1984a) A monoclonal antibody to the human receptor for $\mathrm{T}$ cell growth factor. In: Receptors and Recognition, Vol. 17, Greaves, M., ed., pp. 45-66. Chapman \& Hall, London.

Leonard, W. J., Donlan, T. A., Lebo, R. V. \& Greene, W. C. (1985c) Localization of the gene encoding the human interleukin-2 receptor on chromosome 10. Science 228, 1547.

Leonard, W. J., Krönke, M., Peffer, N. J., Depper, J. M. \& Greene, W. C. (1985d) Interleukin 2 receptor gene expression in normal human T lymphocytes. Proc. Natl. Acad. Sci. USA 82, 6281.

Lowenthal, J. W., Zubler, R. H., Nabholz, M. \& MacDonald, H. R. (1985) Similarities between interleukin 2 receptor number and affinity on activated $B$ and $T$ lymphocytes. Nature 315, 669.

Malek, R. T. \& Ashwell, J. D. (1985) Interleukin-2 upregulates expression of its receptor on a $T$ cell clone. J. Exp. Med. 161, 1575.

Malek, T. R., Robb, R. J. \& Shevach, E. M. (1983) Identification and initial characterization of a rat monoclonal antibody reactive with the murine interleukin 2 receptor ligand complex. Proc. Natl. Acad. Sci. USA 80, 5694.

Miller, J., Malek, T. R., Leonard, W. J., Greene, W. C., Shevach, E. M. \& Germain, J. I. (1985) Nucleotide sequence and expression of a mouse interleukin 2 receptor cDNA. J. Immunol. 134, 4212.

Mittler, R., Rao, P., Olini, G., Westberg, E., Newman, W., Hoffman, M. \& Goldstein, G. (1985) Activated human B cells display a functional IL-2 receptor. J. Immunol. 134, 2393.

Miyawaki, T. A., Yachie, A., Uwandana, N., Ohzeki, S., Nagaoki, T. \& Taniguchi, N. (1982) Functional significance of Tac antigen expressed on activated human T lymphocytes: Tac antigen interacts with $\mathrm{T}$ cell growth factor in cellular proliferation. $J$. Immunol. 129, 2474.

Morgan, D. A., Ruscetti, F. W. \& Gallo, R. C. (1976) Selective in vitro growth of T lymphocytes from normal human bone marrows. Science 193, 1007.

Nakagawa, T., Hirano, T., Nakagawa N., Yoshizaki, K. \& Kishimoto, T. (1985) Effect of recombinant IL-2 and gamma-interferon on proliferation and differentiation of human B cells. J. Immunol. 134, 959.

Neckers, L. M. \& Cossman, J. (1983) Transferrin receptor induction in mitogen stimulated human $\mathrm{T}$ lymphocytes is required for DNA synthesis and cell division and is regulated by interleukin 2. Proc. Natl. Acad. Sci. USA 80, 3494.

Nikaido, T., Shimizu, A., Ishida, N., Sabe, H., Teshigawara, K., Maeda, M., Uchiyama, T., Yodoi, J. \& Honjo, T. (1984) Molecular cloning of cDNA encoding human interleukin 2 receptor. Nature 311, 631.

Ortega-R., G., Robb, R. J., Shevach, E. M. \& Malek, T. R. (1984) The murine IL-2 receptor. I. Monoclonal antibodies that define distinct functional epitopes on activated $\mathrm{T}$ cells and react with activated B cells. J. Immunol. 133, 1970.

Poiesz, B. J., Ruscetti, F. W., Gazdar, A. F., Bunn, P. A., Minna, J. D. \& Gallo, R. C. (1980) Detection and isolation of type $C$ retrovirus particles from fresh and cultured lymphocytes of a patient with cutaneous T cell lymphoma. Proc. Natl. Acad. Sci. USA 77, 7415 . 
Poiesz, B. J., Ruscetti, F. W., Reitz, M. S., Kalyanaraman, V. S. \& Gallo, R. C. (1981) Isolation of a new type $\mathrm{C}$ retrovirus (HTLV) in primary uncultured cells of a patient with Sézary T cell leukemia. Nature 294, 268.

Reem, G. \& Yeh, N.-H. (1984) Interleukin 2 regulates expression of its receptor and synthesis of gamma interferon by human T lymphocytes. Science 225, 429.

Reske-Kunz, A. B., von Steldern, D., Rude, E., Osawa, H. \& Diamantstein, T. (1984) Interleukin 2 receptors on an insulin specific $T$ cell line: dynamics of receptor expression. J. Immunol. 133, 1356.

Robb, R. J. (1984) Interleukin 2: the molecule and its function. Immunol. Today 5, 203.

Robb, R. J. \& Greene, W. C. (1983) Direct demonstration of the identity of T cell growth factor binding protein and the Tac antigen. J. Exp. Med. 158, 1332.

Robb, R. J., Greene, W. C. \& Rusk, C. M. (1984) Low and high affinity cellular receptors for interleukin 2: implications for the level of Tac antigen. J. Exp. Med. 160, 1126.

Robb, R. J., Munck, A. \& Smith, K. A. (1981) T-cell growth factors: quantification, specificity, and biological relevance. J. Exp. Med. 154, 1455.

Rubin, L. A., Kurman, C. L., Biddison, W. E., Goldman, N. D. \& Nelson, D. L. (1985) A monoclonal antibody, $7 \mathrm{G} 7 / \mathrm{B} 6$, binds to an epitope on the human IL-2 receptor that is distinct from that recognized by IL-2 or anti-Tac. Hybridoma 4, 91.

Seiki, M., Eddy, R., Shows, T. \& Yoshida, M. (1984) Nonspecific integration of HTLV provirus genome into adult T-cell leukemia cells. Nature 309, 640.

Seiki, M., Hattori, S., Hirayama, Y. \& Yoshida, M. (1983) Human adult T cell leukemia virus: complete nucleotide sequence of the provirus genome integrated in leukemia cell DNA. Proc. Natl. Acad. Sci. USA 80, 3618.

Seiki, M., Hikikoshi, A., Taniguchi, T. \& Yoshida, M. (1985) Expression of the pX gene of HTLV-I: general splicing mechanism in the HTLV family. Science 228, 1532.

Shackelford, D. A. \& Trowbridge, I. S. (1984) Induction of expression and phosphorylation of the human interleukin 2 receptor by a phorbol diester. J. Biol. Chem. 259, 11706.

Shimotohno, K., Miwa, M., Slamon, D., Chen, I. S., Hoshino, H., Takano, M., Fujino, M. \& Sugimura, T. (1985) Identification of new gene products encoded from X regions of human T cell leukemia viruses. Proc. Natl. Acad. Sci. USA 82, 302.

Smith, K. A. (1980) T-cell growth factor. Immunol. Rev. 51, 337.

Smith, K. A. \& Cantrell, D. A. (1985) Interleukin-2 regulates its own receptor. Proc. Natl. Acad. Sci. USA 82, 864.

Sodroski, J. G., Rosen, C. A. \& Haseltine, W. A. (1984) Trans-acting transcriptional activation of the long terminal repeat of human $T$ lymphotropic viruses in infected cells. Science 225, 381.

Treiger, B. F., Leonard, W. J., Svetlik, P., Rubin, L., Nelson, D. L. \& Greene, W. C. A secreted form of the human inerleukin-2 receptor encoded by an "anchor minus" cDNA. J. Immunol. (in press).

Tsudo, M., Uchiyama, T. \& Uchino, H. (1984) Expression of Tac antigen on activated normal human B cells. J. Exp. Med. 160, 612 .

Uchiyama, T., Broder, S. \& Waldmann, T. A. (1981) A monoclonal antibody (anti-Tac) reactive with activated and functionally mature human T cells. J. Immunol. 126, 1393.

Uchiyama, T., Yodoi, J., Sagawa, K., Takatsuki, K. \& Uchino, H. (1977) Adult T cell leukemia: clinical and hematologic features of 16 cases. Blood $50,481$.

Urdal, D. L., March, C. J., Gillis, S., Larsen, A. \& Dower, S. K. (1984) Purification and chemical characterization of the receptor for interleukin 2 from activated human $T$ lymphocytes and from a human T-cell lymphoma cell line. Proc. Natl. Acad. Sci. USA 81, 6481.

Wachsman, W., Golde, D. W., Temple, P. A., Orr, E. C., Clark, S. C. \& Chen, I. S. Y. (1985) HTLV-X gene product: requirement for the env methionine initiation codon. Science 228, 1534. 
Waldmann, T. A., Goldman, C. K. Robb, R. J., Depper, J. M., Leonard, W. J., Sharrow, S. O., Bongiovanni, K. F., Korsmeyer, S. J. \& Greene, W. C. (1984a) Expression of interleukin 2 receptors on activated human B cells. J. Exp. Med. 160, 1450.

Waldmann, T. A., Greene, W. C., Sarins, P. S., Saxinger, C., Blayney, D. W., Blattner, W. A., Goldman, C. K., Bongiovanni, K., Sharrow, S., Depper, J. M., Leonard, W. J., Uchiyama, T. \& Gallo, R. C. (1984b) Functional and phenotypic comparison of human $\mathrm{T}$ cell leukemia/lymphoma virus positive adult $\mathrm{T}$ cell leukemia with human $\mathrm{T}$ cell leukemia/lymphoma virus negative Sézary leukemia. J. Clin. Invest. 73, 1711.

Wano, Y., Uchiyama, T., Fukui, K., Maeda, M., Uchino, H. \& Yodoi, J. (1984) Characterization of human interleukin 2 receptor (Tac antigen) in normal and leukemic $T$ cells: coexpression of normal and aberrant receptors in HUT 102 cells. J. Immunol. 132, 3005.

Weissman, A. M., Harford, J. B., Svetlik, P. B., Leonard, W. J., Depper, J. M., Waldmann, T. A., Greene, W. C. \& Klausner, R. D. (1986) Only high affinity receptors for interleukin-2 mediate internalization of ligand. Proc. Natl. Acad. Sci. USA (in press).

Welte, K., Andreef, M., Platzer, E., Hollaway, K., Rubin, B., Morre, M. \& Mertelsman, R. (1984) Interleukin 2 regulates the expression of Tac antigen in peripheral blood $T$ lymphocytes. J. Exp. Med. 160, 1390.

Wong-Staal, F. \& Gallo, R. C. (1985) Human T lymphotropic retroviruses. Nature 317, 395.

Yamamoto, T., Davis, C. G., Brown, M. S., Schneider, W. J., Casey, M. L., Goldstein, J. L. \& Russel, D. W. (1984) The human LDL receptor: a cysteine rich protein with multiple Alu sequences in its mRNA. Cell 39, 27.

Yoshida, M., Miyoshi, I. \& Hinuma, Y. (1982) Isolation and characterization of retrovirus from cell lines of human adult $\mathrm{T}$ cell leukemia and its implication in disease. Proc. Natl. Acad. Sci. USA 78, 6476.

Zubler, R. H., Lowenthal, J. W., Erard, F., Hashimoto, N., Devos, R. \& MacDonald, H. R. (1984) Activated B cells express receptors for and proliferate in response to pure interleukin-2. J. Exp. Med. 160, 1170. 
This document is a scanned copy of a printed document. No warranty is given about the accuracy of the copy. Users should refer to the original published version of the material. 